\title{
Prior poliomyelitis-reduced capillary supply and metabolic enzyme content in hypertrophic slow-twitch (type I) muscle fibres
}

\author{
Kristian Borg, Jan Henriksson
}

\begin{abstract}
Capillary supply and oxidative and glycolytic enzyme activities were determined in muscle biopsies from the tibialis anterior muscle in six prior polio patients and a control group. The polio patients, who had paresis and atrophy, but were able to walk normally by making maximal use of all remaining anterior tibial motor units, showed type I (slow-twitch) muscle fibre predominance with a mean (SD) of 98 (2)\% type I fibres versus $81(8) \%$ in the controls $(p<0.01)$ and muscle fibre hypertrophy, the average type $I$ fibre cross-sectional area being $108 \%(p<0.005)$ larger than in the controls. The number of capillaries per muscle fibre was not significantly different from that in the control group, but with the increased muscle fibre area in the polio patients, the capillary density was significantly lower. The number of capillaries in contact with type I fibres relative to fibre area was $40 \%$ lower in the patients than in the controls $(p<0.005)$. The levels of citrate synthase and phosphofructokinase were significantly lower $(38 \%$ and $33 \%$, respectively, $p<0.05$ ) in the

normally but have an excessive overuse of the remaining motor units during walking, which is the main function of the anterior tibial muscle. ${ }^{1}$ In these patients, muscle biopsies showed almost exclusively type I fibres (slowtwitch). There was no decrease, however, in the proportion of motor neurons with high threshold and high axonal conduction velocities, indicating that there was no selective loss of large motor neurons which normally innervate type II muscle fibres (fasttwitch). ${ }^{5}$ Furthermore, Borg et $a l^{5}$ found "promiscuous" fibres, that is muscle fibres containing both slow and fast myosin heavy chains. These fibres corresponded to type I as well as type II fibres according to conventional ATPase staining characteristics and, thus, Borg et $a l^{5}$ suggested that the lack of fibre type differentiation in the polio patients with overuse of remaining anterior tibial motor units was due to a muscle fibre transformation from type II to type I.

The aim of this study was to determine capillary supply and oxidative and glycolytic enzyme activities in the hypertrophic type I mus:le fibres in prior poliomyelitis patients showing overuse of the remaining anterior tibial motor units with a view to explaining the functional capacity of these muscle fibres.
\end{abstract} patients than in the controls, indicating decreased oxidative and glycolytic potentials in the muscle fibres of the polio patients. It is proposed that the abnormal high-frequency activation of all remaining motor units during each step cycle recorded in these patients constitutes a stimulus for type I muscle fibre predominance and hypertrophy but that the overall low muscle usage results in a decreased stimulation of capillary proliferation and mitochondrial enzyme synthesis. The low capillary density and decreased oxidative and glycolytic enzyme potentials might be important factors for the development of muscle weakness, fatigue and muscle pain, which are commonly occurring symptoms in patients with prior poliomyelitis.

Many patients who have had poliomyelitis experience more pronounced or new symptoms decades after the acute infection. Increased muscle weakness, muscle fatigue, muscle pain and even increased muscle atrophy have been described. ${ }^{2-4}$ Prior polio patients with a moderate degree of paresis and atrophy of the tibialis anterior muscle walk

\section{Subjects}

Six patients (four women, two men) with paresis and atrophy of the tibialis anterior muscle due to previous poliomyelitis were examined. The mean age at examination was 57 years (range $37-71$ years). The mean age at onset of poliomyelitis was 22 years (range nine to 48 years) and the mean time between onset and examination was 35 years (range 21-49 years).

The paresis and atrophy of the anterior tibial muscle varied from slight (significant power at full foot dorsiflexion) in five patients to moderate (full foot dorsiflexion without resistance) in the sixth patient. All patients walked unsupported. Five patients reported increased muscle weakness in recent years and four complained of muscle pain. All patients exhibited overuse of the remaining anterior tibial motor units during locomotion, as previously revealed by EMG, and had a predominance of type I muscle fibres as previously described. ${ }^{1}$

Data from the polio patients were compared with data from six healthy volunteers (four women, two men) with a mean age of 41 years (range 23-72 years). 


\section{Methods}

Muscle biopsies of the tibialis anterior muscle were performed by the percutaneous conchotome method originally described by $\operatorname{Radner}^{6}$ and slightly modified. ${ }^{7}$ The biopsy site was carefully selected about $2 \mathrm{~cm}$ laterally from the anterior tibial crista and $5 \mathrm{~cm}$ below the caput fibulae. The biopsy material obtained was freshly frozen in freon 13 kept at its melting point $\left(-190^{\circ} \mathrm{C}\right)$ by liquid nitrogen and stored in a refrigerator at $-75^{\circ} \mathrm{C}$ until further processed. The biopsy material was subdivided for histochemical and biochemical analyses.

\section{HISTOCHEMICAL ANALYSIS}

The material intended for histochemistry was cut (serial transverse sections of $10-15 \mu \mathrm{m}$ ) in a cryostat operating at $-25^{\circ} \mathrm{C}$.

Staining procedures: Myosin-adenosinetriphosphatase (ATPase) by the original method of Padykula and Herman ${ }^{8}$ and the modifications by Brooke and Kaiser $^{9}$ and by the amylase-PAS method to visualise capillaries according to Andersen. ${ }^{10}$

The muscle fibre nomenclature was based on the ATPase stainability according to Brooke and Kaiser. ${ }^{8}$ Thus fibres with a high content of acid-stable ATPase and a low content of alkali-stable ATPase were termed "type I", while fibres with the opposite staining pattern were termed "type II". Subtypes of type II were also determined by using different $\mathrm{pH}$ levels for acid preincubation (4.3 and 4.6). ${ }^{9}$ Thus type II A, B and C fibres could be identified. All fibres in a muscle biopsy cross-section were classified and the total number of fibres of each type was estimated. In the polio patients $0.9 \%$ of the muscle fibres were of type II A and $0.6 \%$ were of type II B or C, and therefore the values of the type II fibres were not processed further.

The sections stained by the amylase-PAS method were photographed and one or several areas (area A) without artifacts produced by the sectioning and staining and without connective tissue structures splitting up the section in different parts were framed by following the cell borders. The total number of fibres of each type in area A was estimated. Both the area of A and fibre type crosssectional areas of all individual muscle fibres in area $\mathrm{A}$ were measured by a semi-automatic technique used on the photographs (MOP Videoplan, Kontron, Bildanalyse $\mathrm{GmbH}$, Munich FRG). The mean (SD) area of A was $1.25(0.21) \mathrm{mm}^{2}$ in the polio patients and 0.97 $(0.21) \mathrm{mm}^{2}$ in the controls.

Capillaries were identified by direct microscopy and if a capillary was cut longitudinally, it was counted as one at each cell junction. ${ }^{11}$ Calculations: Capillary density was calculated as the number of capillaries per $\mathrm{mm}^{2}$ of muscle cross-sectional area.

The capillary-to-fibre ratio was calculated as the total number of capillaries divided by the total number of fibres in area $A$.

The mean number of capillaries in contact with fibres of each type was determined by counting all capillaries around each muscle fibre in area A. Furthermore, the mean number of capillaries in contact with fibres of each type relative to fibre type area (per $1000 \mu \mathrm{m}^{2}$ ) was counted.

\section{BIOCHEMICAL ANALYSIS}

Assays were conducted on homogenates prepared at a dilution of 1:50 (with the exception of the homogenate used for oxoglutarate dehydrogenase, see below) from $15-20 \mathrm{mg}$ muscle specimens that had been weighed at $-20^{\circ} \mathrm{C}$ and given no opportunity to thaw until the moment of homogenisation. The homogenates were prepared in ice-cold medium prepared according to Chi et al, ${ }^{12}$ using all-glass Potter-Elvehjem homogenisers. The resulting crude homogenate was used for spectrophotometric determinations (at $25^{\circ} \mathrm{C}$ ) of citrate synthase (EC 4.1.3.7) and 6-phosphofructokinase (EC 2.7.1.11) ${ }^{1314}$ as well as lactate dehydrogenase (EC 1.1.1.27) and protein. ${ }^{12}$ For oxoglutarate dehydrogenase (EC 1.2.4.2), the homogenisation medium $(1: 10)$ and assay procedure $\left(25^{\circ} \mathrm{C}\right)$ was that of Blomstrand et al. ${ }^{15}$ To minimise the effect of day-to-day variations in the preparation and assays, the muscle samples from patients and controls were analysed simultaneously in random order. All enzyme assays were duplicated under conditions in which reaction rates were proportional to enzyme concentrations.

Reagents. The enzymes were from Sigma Chemical Company (St Louis, Missouri, USA) or Boehringer Mannheim GmbH Biochemica (Mannheim, FRG). Other reagent chemicals were supplied by Sigma Chemical Company or E. Merck (Darmstadt, Germany).

\section{STATISTICAL ANALYSIS}

Mean and standard deviations (SD) were calculated from individual values by standard procedures. The statistical analysis for differences between the groups of polio patients and controls was made by means of the Wilcoxon rank-sum test (two-tailed). $\mathbf{P}<0.05$ was considered statistically significant. For the analysis of correlation, the Spearman rank correlation test was used.

\section{Results}

The mean type I fibre percentage in the whole anterior tibial muscle biopsy cross-section as well as in area $A$ was significantly higher $(p<0.005)$ in the polio patients than in the normal controls (for numerical means, see table). The mean (SD) cross-sectional muscle fibre area [99 (2)\% type I fibres] in area A was significantly larger $(p<0.005)$ and, as a consequence, the number of muscle fibres per $\mathrm{mm}^{2}$ (fibre density) was significantly reduced $(\mathrm{p}<0.01)$ in the polio patients, compared with the controls.

In the polio patients the mean capillary density was significantly lower $(p<0.005)$ than in the controls (table). The capillary-tofibre ratio and the number of capillaries in contact with type I fibres tended to be higher in the polio patients than in the controls. These 
Table Mean (SD) for type I muscle fibre percentage in the whole anterior tibial muscle biopsy and in area A, fibre density, cross-sectional area of type I fibres, capillary density, capillary-to-fibre ratio, number of capillaries in contact with type I fibres (CC-type I) and CC relative to type I fibre area (CC per $1000 \mu^{2}$ ) in the polio patients and the controls. Statistical analysis ( $p)$ by means of the Wilcoxon rank-sum test (two-tailed), n.s. denotes not significant

\begin{tabular}{|c|c|c|c|}
\hline & Polio & Control & Polio-Control ( $p)$ \\
\hline $\begin{array}{l}\text { Type I, \% (whole biopsy) } \\
\text { Type I, \% (in area A) } \\
\text { Fibre density, } \mathrm{n} \\
\text { Type } 1 \text { area, } \mu \mathrm{m}^{2} \\
\text { Capillary density, } \mathrm{n} \\
\text { Capillary-to-fibre ratio, } \mathrm{n} \\
\text { CC-type } \mathrm{I}, \mathrm{n} \\
\text { CC per } 1000 \mu \mathrm{m}^{2}, \mathrm{n}\end{array}$ & $\begin{aligned} & 98 \cdot 0(2 \cdot 1) \\
& 99 \cdot 0(2 \cdot 2) \\
& 87(31) \\
& 11950 \quad(4010) \\
& 270 \quad(56) \\
& 3 \cdot 3(0 \cdot 9) \\
& 6.4(1 \cdot 2) \\
& 0.6(0 \cdot 2)\end{aligned}$ & $\begin{aligned} & 81 \cdot 2(8 \cdot 3) \\
& 85 \cdot 3(8 \cdot 6) \\
& 151(31) \\
& 5730 \quad(1070) \\
& 403(49) \\
& 2.7(0 \cdot 7) \\
& 5.4(0.9) \\
& 1.0(0 \cdot 1)\end{aligned}$ & $\begin{aligned}<0.005 \\
<0.005 \\
<0.01 \\
<0.005 \\
<0.005 \\
\quad \text { n.s. } \\
\quad \text { n.s. } \\
<0.005\end{aligned}$ \\
\hline
\end{tabular}

differences between the groups were, however, not statistically significant. The number of capillaries in contact with type I fibres relative to type I fibre area was significantly lower $(\mathrm{p}<0.005)$ in the patients than in the controls.

In the polio patients the mean levels of citrate synthase and phosphofructokinase were significantly lower $(\mathrm{p}<0.05)$ than in the controls, while the oxoglutarate dehydrogenase and lactate dehydrogenase levels, although displaying the same tendency, did not differ significantly between the groups (fig). In addition, there was a marked variation in levels of citrate synthase, oxoglutarate dehydrogenase and phosphofructokinase in the patients, but not in the controls. The average (SD) value for total muscle protein was identical in the patients and the controls $\left[0.14(0.03) \mathrm{g} \times \mathrm{g}^{-1}\right.$ wet wt in both groups]. There was no significant correlation between enzyme levels and type I fibre percentage in the polio patients. In the controls, the type I fibre percentage correlated with the mean level of citrate synthase $(r=0.92, p<0.01)$ and correlated inversely with lactate dehydrogenase $(r=-0.85, p<0.05)$.

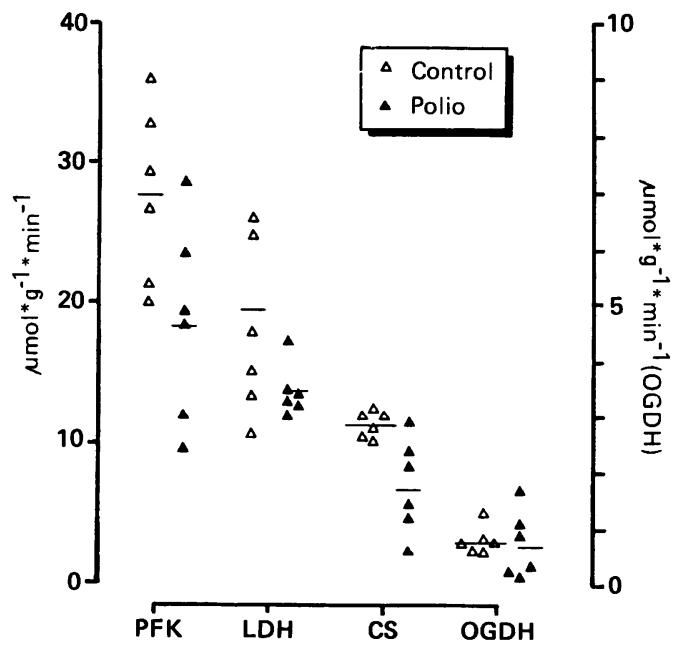

Figure Individual and mean (__ enzyme levels in the anterior tibial muscle biopsy specimens from the prior polio patients and controls in respect of

phosphofructokinase (PFK), lactate dehydrogenase (LDH), citrate synthase (CS) and oxoglutarate dehydrogenase (OGDH). Values in $\mu \mathrm{mol} \times \mathrm{g}^{-1}$ (wet $w t) \times \min ^{-1}$ at $25^{\circ} \mathrm{C}$. The scale for oxoglutarate dehydrogenase is magnified fourfold (right $y$-axis). Citrate synthase and phosphofructokinase were significantly lower in the patients than in the controls ( $p<0.05$, two-tailed Wilcoxon rank-sum test).
The only polio patient who did not complain of recently increased muscle weakness and fatigue had the highest levels of citrate synthase and oxoglutarate dehydrogenase in the patient group, 11.6 and $1.6\left(\mu \mathrm{mol} \times \mathrm{g}^{-1}\right.$ wwt $\times$ $\min ^{-1}$ ), respectively, and also normal levels of phosphofructokinase and lactate dehydrogenase. The mean fibre area $\left(14930 \mu \mathrm{m}^{2}\right)$ was among the highest in the patients while the capillary density ( 276 cap $\times \mathrm{mm}^{-2}$ ) was near the mean for the patient group.

\section{Discussion}

The prior poliomyelitis patients in this study exhibited almost exclusively type I muscle fibres in the anterior tibial muscle, while the controls had $81 \%$ type I fibres, which is within the normal range compared with findings in healthy individuals. ${ }^{16}$ Furthermore, these fibres had an increased cross-sectional area. These findings corroborate earlier studies by Borg et $a l^{15}$ and were assumed to be due to a muscle fibre transformation from fast-twitch type II to slow-twitch type I muscle fibres as a result of increased use of the remaining anterior tibial motor units in analogy with the muscle fibre transformation described in animal experiments using long-term electrical stimulation. ${ }^{17-19}$

High-resistance training has been shown to increase muscle fibre size, most prominently the fast-twitch muscle fibres. ${ }^{2021}$ Depending on the pretraining state of muscle strength, endurance training may also increase the muscle fibre size of all muscle fibre types ${ }^{11}$ or mainly the slowtwitch fibres. ${ }^{22}$ Edström and Ekblom, ${ }^{20}$ however, reported equal fibre sizes in longdistance runners and sedentary controls whilst Houston $e t a^{23}$ reported a reduced fibre size in the gastrocnemius muscle of marathon runners. Andersen and Henriksson ${ }^{11}$ found an increase in capillary density during endurance training and concluded that this type of training was a powerful stimulus for capillary proliferation. Schant $z^{24}$ showed that the number of capillaries per muscle fibre and the muscle fibre area increased equally during heavy-resistance training and thus resulted in an unchanged capillary density. Tesch et al ${ }^{25}$ reported a lower number of capillaries per $\mathrm{mm}^{2}$ in strength-trained subjects than those that were not trained. The number of capillaries per muscle fibre was similar to that in controls in the study by Tesch et al, ${ }^{25}$ and agrees with other studies by Schantz. ${ }^{26}$ It thus seems as if this form of training does not stimulate or, at most, only weakly stimulates capillary neoformation.

In the prior polio patients there was a decrease in capillary density and in the number of capillaries in contact with the muscle fibres relative to the fibre area. In all probability, this was secondary to the fact that the muscle fibres had an increased cross-sectional area. Thus the number of capillaries in contact with the type I fibres was not significantly different in patients and controls. In the polio patients, all remaining anterior tibial motor units were activated sufficiently for fully fused power in each step cycle, at least during short-distance walking. ${ }^{1}$ 
This might resemble to some degree the activation pattern in individuals performing weight training involving high resistance but a relatively low number of repetitions. In terms of the muscle fibre hypertrophy and the resulting "dilution" of muscle capillaries, the muscles of the polio patients bear some resemblance to the muscles of individuals doing high-resistance training. ${ }^{24} 25$ A lowered oxidative and glycolytic potential, as found in the muscles of the prior polio patients of this study, is not a regular finding in strength-trained individuals, ${ }^{26}$ but there are reports of a decreased concentration of mitochondrial (oxidative) enzymes. ${ }^{27} 28$

Although the increased use of the remaining anterior tibial motor units in the step cycle by the polio patients evidently does not result in increased capillary proliferation or mitochondrial oxidative enzyme synthesis, it constitutes a powerful stimulus for muscle fibre transformation as well as for hypertrophy (see above). A fibre type transformation has not been detected after high-resistance training in normal individuals ${ }^{29}$ and the muscle fibre transformation described in animal experiments following long-term electrical stimulation (see above) is, contrary to our results, accompanied by several-fold increases in the muscle content of mitochondrial enzymes. A connection between slow-twitch (type I) fibre preponderance and a high oxidative potential could have been expected, since normal type I muscle fibres have higher levels of oxidative enzymes than type II muscle fibres. ${ }^{3031}$ During endurance training the oxidative enzyme levels increase in both fibre types. ${ }^{12} 32$

The combination of almost type I slowtwitch-fibre predominance and reduced oxidative enzyme content, as observed in this study, therefore appears to be a unique feature of prior polio muscle. This apparent paradox may be explained by the abnormal motor-unit activation pattern that has recently been described. ${ }^{153}$ It was shown that all remaining anterior tibial motor units are activated at high frequencies $(20-40 \mathrm{~Hz})$ more than 10 times per step cycle during short-distance walking but that the gait pattern is changed so that the strain on the anterior tibial muscle decreases during long-distance walking. Thus although there is an overuse of high-threshold units in most step cycles, the overall muscle usage may be low, thereby resulting in a low content of metabolic enzymes. The conventional myofibrillar ATPase staining in this case slightly underestimates the muscle content of fast myosin since up to $1 / 10$ of the type I muscle fibres may contain both slow and fast myosin isoforms (promiscuous fibres, 5). From the EMG results, ${ }^{5}$ it is also evident that part of the structurally identified type I fibres in this patient group belong to motor units that have high threshold and high axonal conduction velocities. In accordance with our findings, an abnormally low oxidative enzyme activity in the vastus lateralis of the quadriceps femoris muscle was recently described in prior polio patients ${ }^{34}$ and was ascribed to a low level of physical activity. The oxidative enzyme activity increased after training. ${ }^{35}$
The reduced capillary supply in relation to fibre area in the polio patients indicates a decreased diffusion capacity in the muscle fibre due to an increased diffusion distance. This might lead to a shortage of substrate during muscle work, an assumption which is further supported by the low oxidative and glycolytic capacities of the muscle fibres. These factors might be important for the development of muscle fatigue, especially the post-exercise fatigue, myalgia and transient decrease in strength which are commonly occurring symptoms in patients who have had polio. ${ }^{34}$

This study was supported by grants from the Swedish Medical Research Council (B89-12X-03875-13C, B87-14X-07917), the Swedish Sports Research Council, the King Gustaf V Research Foundation, the Swedish Association for Traffic and Polio Disabled, the Norrbacka-Eugenia Foundation, the Swedish grateful to Ms Birgitta Lindegren and Ms Birgitta Hedberg for excellent technical assistance.

1 Borg K, Borg J, Edström L, Grimby L. Effects of excessive use of remaining muscle fibers in prior polio and $\mathrm{L} \mathrm{V}$ lesion. Muscle Nerve 1988;11:1219-30.

2 Dalakas MS, Sever JL, Madden DL, et al. Late postpoliomyelitis muscular atrophy: Clinical, virologic and immunologic studies. Rev Infect Dis 1984;6(suppl 2): S562-7.

3 Halstead LS, Rossi CD. Post-polio syndrome: clinical experience with 132 consecutive outpatients. In: Halstead LS, Wiechers DO, eds. Research and clinical aspects of the late effects of poliomyelitis. Birth defects: original article series 1987;23(4):13-26.

4 Maynard FM. Differential diagnosis of pain and weakness in post-polio patients. In: Halstead LS, Wiechers DO, eds. post-polio patients. In: Halstead LS, Wiechers DO, eds.
Late effects of poliomyelitis. Miami, Florida: Symposia Late effects of poliomyelitis

5 Borg K, Borg J, Dhoot GK, Edström L, Grimby L, Thornell $\mathrm{L}-\mathrm{E}$. Motoneurone firing and isomyosin type of muscle fibres in prior polio. J Neurol Neurosurg Psychiatry 1989; 52:1141-8.

6 Radner S. Knappnalsteknik för iterativ muskelbiopsi. Stockholm: Trans Swedish Soc Med Sci XIX 1962:94.

7 Lindholm $T$. The influence of uraemia and electrolyte disturbances on muscle action potentials and motor nerve conduction in man. Acta Med Scand 1968;(Suppl):491.

8 Padykula HA, Herman E. The specificity of the histochemical method for adenosine triphosphatase. $J$ Histochem Cytochem 1955;3:170-83.

9 Brooke MH, Kaiser KK. Muscle fiber types-How many and what kind? Arch Neurol (Chic) 1970;23:369-79.

10 Andersen P. Capillary density in skeletal muscle of man. Acta Physiol Scand 1975;95:203-5.

11 Andersen P, Henriksson J. Capillary supply of the quadriceps femoris muscle of man: Adaptive response to exercise. J Physiol (Lond) 1977;270:677-90.

12 Chi MM-Y, Hintz CS, Coyle EF, et al. Effects of detraining on enzymes of energy metabolism in individual human muscle fibers. Am J Physiol 1983;244:C276-87.

13 Opie LH, Newsholme EA. The activities of fructose 1,6diphosphatase, phosphofructokinase, and phosphoenolpyruvate carboxykinase in white muscle and red muscle. Biochem J 1967;103:391-9.

14 Alp PR, Newsholme EA, Zammit VA. Activities of citrate synthase and $\mathrm{NAD}^{+}$-linked and $\mathrm{NADP}^{+}$-linked isocitrate dehydrogenase in muscle from vertebrates and invertebrates. Biochem J 1976;154:689-700.

15 Blomstrand E, Challis RAJ, Cooney GJ, Newsholme EA. Maximal activities of hexokinase, 6-phosphofructokinase, Maximal activities of hexokinase, 6-phosphofructokinase, transferase in rat and avian muscles. Biosci Rep 1983;3: transferase

16 Jakobsson F, Borg K, Edström L, Grimby L. Use of motor units in relation to muscle fiber type and size in man. Muscle Nerve 1988;11:1211-18.

17 Salmons S, Henriksson J. The adaptive response of skeleta muscle to increased use. Muscle Nerve 1981;4:94-105.

18 Jolesz F, Sréter FA. Development, innervation, and activitypattern induced changes in skeletal muscle. Ann Rev Physiol 1981;43:531-52.

19 Pette D, Vrbovà G. Neural control of phenotypic expression in mammalian muscle fibers. Muscle Nerve 1985;8: 676-89.

20 Edström L, Ekblom B. Differences in sizes of red and white muscle fibres in vastus lateralis of musculus quadriceps femoris of normal individuals and athletes. Relation to physical performance. Scand J Clin Lab Invest 1972;30: physical pe.

21 Tesch P, Larsson L. Muscle hypertrophy in bodybuilders. Eur J Appl Physiol 1982;49:301-6.

22 Gollnick PD, Armstrong RB, Saltin B, Saubert IVCW, Sembrowich WL, Shepherd RE. Effect of training on enzyme activity and fiber composition of human skeletal muscle. J Appl Physiol 1973;34:107-11. 
23 Houston ME, Bentzen $H$, Larsen $H$. Interrelationships between skeletal muscle adaptations and performance as studied by detraining and retraining. Acta Physiol Scand 1979;105:163-70.

24 Schantz P. Capillary supply in hypertrophied human skeletal muscle. Acta Physiol Scand 1982;114:635-7.

25 Tesch PA, Thorsson A, Kaiser P. Muscle capillary supply and fiber type characteristics in weight and power lifters. and fiber type characteristics in

26 Schantz PG, Källman $M$. Levels of shuttle enzymes and cytochrome B5 reductase in human skeletal muscle: effect of strength training. J Appl Physiol 1989;67(1):123-7.

27 Gollnick PD, Armstrong RB, Saubert IVCW, Piehl K Saltin B. Enzyme activity and fiber composition in skeleta muscle of untrained and trained men. J Appl Physiol 1972;33:312-19.

28 MacDougall JD, Sale DG, Moroz JR, Elder GCB, Sutton $\mathrm{J}$, Howald $\mathrm{H}$. Mitochondrial volume density in huma skeletal muscle following heavy resistance training. Med Sci in Sports 1979;11:164-6.

29 Saltin B, Gollnick PD. Skeletal muscle adaptability: significance for metabolism and performance. In: Handbook of physiology, 10. Skeletal muscle (Am Physiol Soc) Baltimore: Williams and Wilkins Company, 1983:
555-631.

30 Henriksson J, Reitman J. Quantitative measures of enzyme activities in type I and type II muscle fibres of man after training. Acta Physiol Scand 1976;97:392-7.

31 Essén B, Jansson E, Henriksson J, Taylor AW, Saltin B Metabolic characteristics of fibre types in human skeletal muscle. Acta Physiol Scand 1975;95:153-65.

32 Essén-Gustavsson B, Henriksson J. Enzyme levels in pools of microdissected human muscle fibres of identified type. Adaptive response to exercise. Acta Physiol Scand Adaptive respons

33 Grimby L, Sjöström L. Flexibility of the use of residual tibial anterior motor units during walking in neuromuscular diseases. Scand J Rehab Med (in press)

34 Grimby G, Einarsson G. Muscle morphology with special reference to muscle strength in post-polio subjects. In Halstead LS, Wiechers DO, eds. Research and clinical aspects of the late effects of poliomyelitis. Birth defects. original article series 1987;23(4):265-74.

35 Einarsson G, Grimby G. Strengthening exercise program in post-polio subjects. In: Halstead LS, Wiechers DO, eds. Research and clinical aspects of the late effects of poliomyelitis. Birth defects: original article series 1987;23 (4):275-83. 